\title{
HOW UP SO DOWN
}

Author: Denes Joo, Architect-Urbanist, Systemic Evolutions \& Pyramids Independent Researcher.

Abstract: In continuation of the Terrestrial Projections of the Cosmic Environmental Connections [1], it's detailed the European Continental Territory, inside it focusing on the Central European Area. The unsuccessful functioning of the Hybrid European Union is shoring up the pressing necessity for a normal environmental-territorial, humansocial and economical efficient reorganizing of Europe, with a synergic functioning based on cosmic principles, namely corresponding to the cosmic structure and functioning organized around the Constellation Draco (Carpathian Mountains) [2], with the Nebula NGC 6543 called „Cat's Eye” inside, as Ecliptic Pole (the Rosia Poieni Peak in the WestCarpathians, Romania).

Context: At the beginning, the mythological robbing of Europe by Zeus indicates the former central position and role of the Olympus Mountain in the actual Balcanic territory. Really the actual mountain and its surroundings are the remains of a large mountain-pyramid, before the forming of the Carpathian-Chain as the second projection of the Constellation Draco on the Earth, with its centre as Ecliptic Pole, in form of the large mountain-pyramid ROSIA POIENI inside the Western-Carpathians, Romania (2A) (2B) [3]. So, in the course of the cosmic evolution of the Photon-Belt (1A), the centre of Europe was replaced, but without taking into consideration this fact in the territorial organizing of Europe inside the Eurasian and Terrestrial context, especially after the coming into existence of the Hybrid European Union.
Concept: Based on the Hermetic Principle „How up so down”, the cosmic structure and events are reflected on the Earth, evolving inside the Solar System along his solenoid-like cyclic movement on the Photon-Belt (1A). This reflection is visible especially on the Earth's surface, along the crust-forming process of the initial heat drop, which is transforming from the toroidal to the spherical form [4]. In the spherical state are 4 positional phases distinguishable relatively to the Sun: 1) Moon-like one-sided; 2) rocking; 3) first-equatorial; 4) second -equatorial (4A) (4B). The projection of the central element of the Photon-Belt-System - the Constellation Draco, with the Ecliptic Pole inside - took place in the 3) and 4) positional phases, around 500-480 million, respectively 250-200 (plicated phase, exterior range) and 15-9 million years ago (volcanic phase, interior range), in form of the Asian (1C), respectively European Carpathians (2B) (3), the last being the bottom of the Eurasian Bird (1C) [5], and inside them the Ecliptic North Pole being the Rosia Poieni Peak (2B) (3) [3]. In this vision it's opportune to take into consideration the „How up so down” principle in the territorial organizing of the Central European Area, especially around the Carpathian-Chain, and of the whole Old Europe.

Description: During the terrestrial evolution, the global civilizations were taking shape only in the last million years, with guiding centres on the continentdimensional oceanic isles (2): 1) Hyperborean - Arctic Ocean - Thule; 2) Agartha - Indian ocean - Ma; 3) Maya - 
Pacific Ocean - Mu; 4) Atlantic - Atlantic Ocean - Atl; except 5) Arya - Asian Continent - Tibet [6]. The continental civilizations - being conditioned by the presence of the water - were formed naturally according to the river-basins [7], but in many cases they were and are „organized” after other principles, e.g. the 13 European ,kingdoms" after the Napoleonean wars, just like the first 13 „states" in the United States of America. This $12+1$ organizing reminds us of the ancestral Hesiodean dodeca-divine structure, between them the 12 Olympean Gods too. The ancestral people employed the 6 or $6+1$ model too, the first in form of $2 \times 3$ components [6]. The starting-point of all these organizing-models' is the terrestrial projection/reflection of the Constellation Draco/Dragon, the celestial representation of the draconic cosmic race [8], surrounded by 12 reptilian and many mammal constellations, in order of their evolution. The first/Asian projection represents the crop, respectively the second/European projection - the Carpathian Mountains, elongated in both directions - the bottom of the Eurasian Bird (1C). The European Carpathians (3) are evolved near the E-W Eurasian Mountain-chain, the spinal column of the Eurasian Bird, but both interrupted by the Crete Sea - Kyklades - Egean Sea Dardanelles-strait - Marmara Sea Boshporus/Bas-boreus (=Boreus-invicted)strait, and transforming it in the Balcanic Mountains - fastening the projection of the Constellation Ursa Minor - with a new continuation from Sofia as Rodope Mountains on the Balcanic territory, and so making disappear the bottom of the Dragon near the South-coast of the Black Sea and through it to Sevastopol, the tailend of the Dragon. So, the transformed projection of the Constellation Draco - the initial European Carpathians - was shortened by this end. The other end begins with the head of the Dragon (Moravian Basin) and is continuing with the chest and forelegs (Slovakian Mountains), waist/back (East Carpathians), thighs (South Carpathians) and hindlegs (Balcanic Carpathians). In other words, the tail of the Dragon was cut, the European Carpathian-chain was clearly separated from the Asian part (3). In this context, the Olympus Mountain was (and it is!) the projection of the load-star Thuban. After the name of the constellation, let call we this CentralEuropean territory DRAKYA (3), separated by the Danube River in NorthDrakya = DAKYA, and South-Drakya = TRAKYA, bordered by the North-, respectively South-European Sees, and Dnester-Bug line to East, respectively Trieste-Szczecin line to West, with directing centre in the proposed new town, called Whole Periodic City „ROSIA POIENI" [3], the projection of the Ecliptic Centre. This Central-European Territory - with the former GermanRoman Empire territory together - is forming the Central European Area, which is surrounded by the East-, Northand West-European Areas, together forming the European Continent. This continental organizing is suited to the ancestral $2 \times 3$ global self-organizing model [6], but instead of $2 \times 3 \times 4$ with $2 \times 3 \times 5$ continental areas, with areal selfgovernment based on elections in every fifth year, and with government role after every 30 years. In this European Continental Territory don't takes part the Russian territory, it's considered separate, in context of the Eurasian Bird. Similarly to the new Whole Periodic City ROSIA 
POIENI in the Carpathians for DRAKYA, it will be necessary to realize new guiding centres for every continental area, reconsidering the whole settlement network and highway-system, taking into consideration the energetic grid of the Earth (4A) (4B) [6] [9], and the new possibilities of the dimensional energy and cronovisor systems, in correlation with the balanced evolution of Our Planet, putting back the Cosmic Harmony.

Conclusions: Based on the global cosmic interactions, expressed in the form of the ancient Hermetic Principle „How up so down", into a systemic view [10] [11] it's possible to conclude former or future events, respectively the most efficient evolutionary lines on every existencial level. So, after the ethnic, religious, social, economic, territorial and many other fragmentations - in other words atomizations - it's time to restructure the whole terrestrial civilization, and inside it the European Civilization, which many centuries ago is looking only for itself. Instead of the actual unicriterial (e.g. nationality) systems it's necessary a synergy of multicriterial systems. The above sketched idea offers the possibility to elaborate a fertile organizational model for the terrestrial - inside which the whole European - restucturing.

\section{Annexes:}

(1A) - Structure of the Local Universe; (1B) - Ecliptic Axis; (1C) - Eurasian Bird;

(2) - Terrestrial Civilization Centres (in the last million years);

(2A) - The Constellation Draco in the Polar Circle; (2B) - The Carpathian Vortex;
(3) - Organizing of the Central European Territory (Drakya=Dakya+Trakya);

(4A) - The Energy-Grid of the Earth; (4B) - Dragon-Lines System of the Earth.

References: [1] - Joo, D.: Terrestrial Projections of the Cosmic Environmental Connections, paper submitted for the IRED Conference Kuala Lumpur City,Malaysia, 03-04 February 2018; [2] - Lovinescu, V.: Dacia Hiperboreana (RO), 1936-37/199496; [3] - Joo, D., Lazar, Gy.: The Whole Periodic City „Rosia Poieni”, INCD URBAN-INCERC Conference 2017, ClujNapoca, Romania; [4] - Joo, D.: A ConicToroidal Model of the Material World, Materials Research Conference 2017, Berlin, Germany; [5] - Churchward, J.: The Lost Continent of Mu, 1974; [6] - Joó, D.: Golden Mean or/and Chaos? The Future in the View of Hungary, 1998; [7] Valev, E. B.: Economical Organizing Project of the East-European Socialist Countries, Revista Economica (RO) No. 1/1964; [8] - Joo, D.: Cosmic Connections of the Pyramid Complexes, ICBP BOOK, The Proceedings, 2008; [9] - Gusti, G.: The Complex Organizing of the Romanian Territory (RO), 1964; [10] - Joó, D.: Proposal of Mathematical Model for the Futures Research, Arhitectura (RO) No. 1/1984; [11] - Joó, D.: Ideas Referring to a Mathematical Model I.-II., Arhitectura (RO) No. 5/1984, 3/1986.

Biography: Denes JOO, after the Architecture and Urbanism University in Bucharest, he studied Mathematics, Economy, Sociology in Cluj-Napoca-city, and Postgradual Settlement and Regional Planning in Bucharest, and parallel with all these Physics, Chemistry, History, Astronomy, Philosophy and other scientific disciplines without limits (and titles). 
Elaborating new mathematical prognosis models, he extended the FuturesResearch to the Systemic Evolutions Research, as a new synthesis in the science, extending it from the terrestrial to the cosmic evolution, from the micro- to the macro-world, including the pyramids research too, the results being reflected between others in the extended Whole Periodic

System (denesjoo.wordpress.com).

Budapest, 25th January 2018. 